REVIEW

\title{
The endocrine system in chronic nitric oxide deficiency
}

Félix Vargas, Juan Manuel Moreno ${ }^{1}$, Rosemary Wangensteen ${ }^{2}$, Isabel Rodríguez-Gómez and Joaquín García-Estañ ${ }^{3}$

Departamento de Fisiología, Facultad de Medicina, Universidad de Granada, E-18012 Granada, Spain, ${ }^{1}$ Servicio de Nefrología, U. Experimental, Hospital Virgen de las Nieves, Granada, Spain, ${ }^{2}$ Área de Fisiología, Universidad de Jaén, Jaén, Spain and ${ }^{3}$ Departamento de Fisiología, Facultad de Medicina, Universidad de Murcia, Murcia, Spain

(Correspondence should be addressed to F Vargas; Email: fvargas@ugr.es)

\begin{abstract}
The experimental model of chronic inhibition of nitric oxide (NO) production has proven to be a useful tool to study cardiovascular and renal lesions produced by this type of hypertension, which are similar to those found in human hypertension. It also offers a unique opportunity to study the interaction of NO with the humoral systems, known to have a role in the normal physiology of vascular tone and renal function. This review provides a thorough and updated analysis of the interactions of NO with the endocrine system. There is special focus on the main vasoactive factors, including the reninangiotensin-aldosterone system, catecholamines, vasopressin, and endothelin among others. Recent discoveries of crosstalk between the endocrine system and NO are also reported. Study of these humoral interactions indicates that NO is a molecule with ubiquitous function and that its inhibition alters virtually to all other known regulatory systems. Thus, hypothyroidism attenuates the pressor effect of NO inhibitor N-nitro-L-arginine methyl ester, whereas hyperthyroidism aggravates the effects of NO synthesis inhibition; the sex hormone environment determines the blood pressure response to NO blockade; NO may play a homeostatic role against the prohypertensive effects of mineralocorticoids, thyroid hormones and insulin; and finally, NO deficiency affects not only blood pressure but also glucose and lipid homeostasis, mimicking the human metabolic syndrome X, suggesting that NO deficiency may be a link between metabolic and cardiovascular disease.
\end{abstract}

European Journal of Endocrinology 156 1-12

\section{Introduction}

Over the past 15 years, numerous experimental studies have demonstrated the diverse functions and roles of nitric oxide (NO) in normal physiology and in different disease states. NO is known to be synthesized in many cells and tissues by actions of NO synthases (NOS), which catalyze the conversion of L-arginine into L-citrulline with NO as the product. NO mediates its effects by rapid penetration of the target cell membrane and stimulation of soluble guanylate cyclase to produce its second messenger, cyclic guanosine monophosphate (cGMP). Acute, and chronic administrations of Larginine analogs, which non-specifically inhibit NOS isoforms, are associated with renal and cardiovascular functional and structural alterations that have been studied in detail over the past years. Thus, a new NO-deficient model of arterial hypertension based on chronic use of these inhibitors, e.g., N-nitro-L-arginine methyl ester (L-NAME), has allowed researchers to study the role of NO in the long-term control of blood pressure (BP) and its interactions with the other humoral mediators that control vascular tone and renal function. Several articles can be recommended to the interested reader for an account of the hypertensive model itself
(1-3). The present review focuses on the interaction between NO and the endocrine system, and on the role of the hormones directly or indirectly related to BP control in the pathophysiology of NO-deficient arterial hypertension.

\section{Vasoactive hormones}

\section{The renin-angiotensin system (RAS)}

Many in vivo and in vitro studies have been performed to characterize the physiological role of NO in the control of renal renin synthesis and secretion. Several in vitro studies using different preparations have provided evidence that NO might act as an inhibitor of renin release. Thus, NO inhibition of renin release was reported by Vidal et al. (4) in a bioassay of cortical slices of canine kidney superfused with a solution flowing through the carotid artery and by Greenberg et al. (5) in their study of isolated juxtaglomerular granular cells. However, other in vitro studies of afferent arterioles isolated from rat kidney (6) or isolated perfused kidneys (7) suggested that NO stimulates the synthesis and/or secretion of renin. These discrepancies may be related to the presence of two enzymes, 
endothelial NOS (eNOS) and neuronal NOS (nNOS), with different localizations in the kidney and producing the same product NO. The activity of eNOS and macula densa nNOS show opposite responses to changes in the extracellular volume in order to restore the sodium balance and it has even been proposed that endothelium-generated NO directly inhibits macula densa nNOS (8). Endothelium-derived NO appears to be important for buffering minute-to-minute variations in perfusion pressure and rapid changes in angiotensin II activity. In contrast, macula densa nNOS has been proposed to regulate adaptation to long-term changes in distal delivery and is considered a mediator of renin formation (8). Macula densa nNOS expression is regulated in parallel with renin expression under a variety of conditions $(9,10)$. Macula densa nNOS and renin expression increased in rats treated with furosemide for 5 days and in rats placed on a low sodium diet (9). nNOS has also been shown to be sensitive to sodium intake, which was negatively related to nNOS and renin expression in renal cortical slices from salt-restricted, normal, and salt-loaded rats (10).

The increase in renin release during an acute decrease in perfusion pressure was inhibited by non-selective NOS inhibition in conscious dogs (11). However, administration to rats of 7-nitroindazole, a relative inhibitor of nNOS, which fully inhibited a furosemide-induced increase in renin secretion, did not modify renin release after acute decrease in perfusion pressure in rats (12). Although these acute studies indicate an important role for nNOS-derived NO in the stimulation of renin release, chronic administration of 7-nitroindazole (4-6 weeks) to normal rats increased plasma renin activity and did not modify inhibitory effects on renin release, induced by chronic desoxycorticosterone (DOCA) administration or by changes in sodium intake $(13,14)$.

Plasma renin activity (PRA) shows a heterogeneous pattern in nitric oxide (NO) inhibition-induced arterial hypertension in rats (1). Nevertheless, many animal studies have indicated that the RAS plays an important role in this type of hypertension, presenting evidence of a functional balance between angiotensin II (AII) and NO $(15,16)$.

The acute administration of AII inhibitors to L-NAME hypertensive rats has yielded contradictory results. Thus, Zanchi et al. (9) obtained a large BP reduction with angiotensin type $1\left(\mathrm{AT}_{1}\right)$ receptor blockade, whereas other authors $(17,18)$ observed less effect of AII blockade on BP or renal hemodynamics in rats with chronic NOS inhibition. Although studies of acute inhibition of AII in the chronic NOS inhibition model have yielded inconclusive results, the participation of the RAS in this type of hypertension is supported by data showing that chronic RAS blockade prevents or attenuates and reverses L-NAME hypertension in rats. Thus, in the first study of this model of hypertension, Ribeiro et al. (19) showed that chronic co-administration of the $\mathrm{AT}_{1}$ receptor antagonist losartan to rats chronically treated with L-NAME, prevented both the hypertension and the renal injury associated with this model, suggesting a key participation of the RAS in these events. These findings were confirmed and extended by several laboratories using chronic administration of AII receptor antagonists or angiotensinconverting enzyme (ACE) inhibitors (20-22). In addition, chronic AII blockade reversed established hypertension (23) and reduced remaining BP elevation after NO inhibition withdrawal (24). Chronic administration of an $\mathrm{AT}_{1}$ antagonist or ACE inhibitor prevented arterial hypertension, as reported above, and improved renal hemodynamics, but the pressure-diuresis and -natriuresis responses were not normalized, despite normalization of the elevated BP and showed very similar slopes to those of hypertensive untreated rats (22). According to these observations, although angiotensin blockade reduces BP, it is not able to overcome renal alterations produced by NO deficiency.

ACE and neutral endopeptidase (NEP) are cell membrane-bound zinc metallopeptidases with close homology at their catalytic sites and several common substrates (25). Omapatrilat is a mercaptoacyl derivative of a dipeptide surrogate that simultaneously inhibits both ACE and NEP in vitro (25) and in vivo (26). Inhibition of NEP protects vasodilator peptides (natriuretic peptides, bradykinin, and adrenomedullin) from degradation and reduces BP in low renin states (27-29). ACE inhibition attenuates the formation of AII and lowers BP in low, normal, and high renin experimental models of hypertension in rats (27) and in spontaneously hypertensive rats (30). Omapatrilat exerts important preventive effects on hypertension and renal injury in rats treated with L-NAME plus DOCA (31), which would be due to vasopeptidase inhibition since chronic AII blockade is completely ineffective in this experimental model (19).

In summary, experimental evidence obtained from in vitro or acute experiments indicates that the $\mathrm{NO}$ signal from macula densa cells is very important for renin release. Thus, macula densa cells are rich in nNOS and macula densa nNOS expression is regulated in parallel with renin expression under various situations that increase or decrease renin secretion. However, doubts about the role of nNOS in the long-term control of renin secretion have been raised by chronic studies showing that nNOS blockade does not interfere with the counterbalance between renin and an increased sodium intake or retention. Regarding the role of the RAS in BP and other cardiovascular and renal manifestations after NO blockade, acute experiments yielded contradictory results but chronic studies blocking the RAS, indicated that this system plays a major role in NO-inhibitioninduced hypertension. In fact, a functional balance exists between NO and AII, suggesting that AII predominates and promotes cardiovascular and renal injury in clinical diseases with reduced NO production, such as diabetes or atherosclerosis. 


\section{Catecholamines}

NO is hypothesized to be an inhibitory modulator of central sympathetic nervous outflow, and deficient neuronal NO production is thought to cause sympathetic overactivity that can contribute to NO-deficient arterial hypertension (32). This has led to speculation that NO-deficient hypertension is caused not only by attenuation of endothelium-dependent vasodilatation but also by inhibition of NO production at other sites (32). Elevated plasma norepinephrine and epinephrine concentrations were found in L-NAME hypertensive rats (9, 33), whereas Liu et al. (34) reported unchanged plasma catecholamine levels and decreased urinary levels of norepinephrine and epinephrine.

Studies of the effects of sympathetic blockade on the acute BP response to NOS inhibition have also yielded contradictory results. Some studies in conscious (35) or anesthetized rats (36) identified a major neurogenic component in the BP elevation, induced by acute NOS inhibition, whereas other studies $(37,38)$ drew diametrically opposed conclusions.

Acute inhibition of the adrenergic system in the L-NAME hypertension rat model has also produced variable results with a substantial fall (9) and less change in BP, (18) both reported during acute $\alpha 1$-adrenergic blockade. On the other hand, acute ganglionic blockade produced a larger fall in BP in rats with chronic NOS inhibition than in controls (39). Short-term sympathectomy attenuated the hypertension induced by 6 days of L-NAME administration in rats (40), suggesting that increased central sympathetic drive may be involved in chronic NOS inhibition-induced hypertension. Sander and Victor (32) also evaluated the contribution of the adrenergic system in the acute (30 min and $6 \mathrm{~h}$ ) and early ( 6 days) phases of NO-deficient hypertension and suggested that the neurogenic component increases overtime and that an intact adrenergic system is necessary for the full expression and maintenance of this type of hypertension. In consonance with this finding, it was demonstrated that the hypertension of diabetic L-NAME-treated rats depends on an intact sympathetic nervous system (41). Our group reported that long-term administration of the $\alpha 1$-receptor antagonist prazosin markedly attenuates hypertension and renal injury in chronically L-NAME-treated rats, suggesting that adrenergic tone plays an important role in the long-term control of BP and in renal abnormalities after NO blockade. It is interesting to note that prazosin also exerts important preventive effects on hypertension and renal injury in rats treated with L-NAME plus DOCA (42), transforming L-NAME hypertension into an AIIindependent model in, which chronic AII blockade is completely ineffective (21). These findings indicate that when PRA is suppressed by DOCA in L-NAME hypertension, the increased BP and renal injury are largely dependent on the adrenergic system.
Available data appear to indicate that sympathetic overactivity follows NO inhibition and that the sympathetic nervous system plays a major role in the hypertension induced by chronic NO inhibition, especially when the RAS is suppressed. Moreover, a counterbalance between NO and the sympathetic nervous system is suggested, as occurs with the RAS and other vasoconstrictor systems.

\section{Vasopressin}

Several studies have demonstrated an important role for nNOS in the regulation of drinking behavior in rats (43). Our group reported that administration of the nNOS inhibitor 7 -nitroindazole $(7 \mathrm{NI})(44,45)$ to normal rats produced a mild polyuria-polydipsia syndrome (13). This phenomenon has been attributed to an inhibitory effect of $7 \mathrm{NI}$ on the release of arginine vasopressin (AVP), because nNOS and AVP are co-localized in supraoptic and paraventricular nuclei (43), and other forebrain structures that participate in the regulation of drinking behavior. Moreover, the systemic administration of $7 \mathrm{NI}$ was shown to inhibit the increase in plasma AVP produced by salt loading in rats (46) and to reverse the elevated AVP induced by cirrhosis in rats $(47)$.

In chronic L-NAME-treated rats, plasma AVP levels have been reported to be unchanged (34), whereas our group observed that total urinary excretion of immunoreactive AVP was significantly increased (48). However, when these animals received $1 \% \mathrm{NaCl}$ as drinking fluid, L-NAME treatment produced no additional increase in urinary AVP excretion, greater than that produced by the increased saline intake, despite producing a greater BP increase (48).

At vascular level, the active wall tension of resistance mesenteric arteries from rats treated with L-NAME for 4 weeks showed an unaltered responsiveness to vasopres$\sin (49)$.

All of these results suggest that vasopressin does not play an important role in BP elevation under chronic NO deficiency. However, further studies using specific blockers of AVP receptors are required to determine the contribution of this vasoactive hormone to the increased BP and renal injury that follows NO inhibition.

\section{Endothelin}

Vanhoutte et al. (50) proposed an interaction between endothelium-derived vasorelaxing and vasoconstricting factors. Studies of porcine aorta have shown that NO downregulates endothelin (ET)-1 expression by endothelial cells, may blunt the release of ET (51) and is a potent antagonist of endothelin-induced stimulation of vascular smooth muscle (52). Thus, NO has been described as a physiological antagonist of ET-induced contractions (50) that is, therefore able to participate in 
the cardiovascular effects induced by NO inhibition. The pressor effect induced in rats by acute NO inhibition with L-NAME injection is attenuated by ET blockade but is very dependent on the activation of endothelin receptors (53-55). Bosentan, an ET inhibitor, acutely decreased BP in L-NAME hypertensive rats (56). However, chronic ET blockade did not alter the arterial hypertension exhibited by the chronic NO deficiency rat model (56-59) and mesenteric resistance arteries showed unchanged responsiveness to ET in rats under chronic L-NAME treatment for 4 weeks (49). Hence, these data and those showing that chronic L-NAME does not increase plasma ET levels $(58,59)$ or ET-1 mRNA levels in rat aorta or mesenteric arteries (60) suggest that ET does not participate in developing or maintaining the hypertension produced by chronic NO inhibition in the rat. In contrast, with the unchanged plasma values, increased levels of urinary ET excretion have been reported in L-NAME-treated rats $(58,61)$, suggesting that urinary ET derives from the kidney $(33,58,59)$ and supporting an interaction between NO and ET, at least at renal level. Given the profound renal effects of ET, i.e., decreased glomerular filtration rate (GFR) and renal blood flow (RBF) (62), our group proposed its possible involvement in developing and maintaining the renal dysfunction associated with chronic NO deficiency (61). In fact, chronic treatment with bosentan did not attenuate the arterial hypertension of L-NAME-treated rats but normalized GFR and RBF (63), suggesting that the renal vasoconstriction observed in the L-NAME hypertensive rat is related to elevated intrarenal levels of this vasoconstrictor. However, in spite of the beneficial effect of bosentan on the reduced renal hemodynamics of L-NAME-treated rats, this treatment did not normalize the excretory function, which was only moderately increased. These observations suggest that the lower pressure-diuretic- and-natriuretic responses of L-NAME hypertensive rats is mainly due to an enhanced tubular reabsorption, since the GFR and RBF normalization observed with bosentan was not sufficient to normalize the elimination of sodium and water, although chronic bosentan significantly improved the pressure-natriuretic response (63).

In summary, published results indicate that ET participates in the renal hemodynamic and excretory alterations produced by the chronic inhibition of NO synthesis. However, the BP increase in this model is not mediated by ET activation. Therefore, the proposed interaction between NO and ET appears to occur solely at renal level, where it participates in the renal dysfunction produced by chronic NO deficiency but not in long-term BP control.

\section{Thyroid hormones}

Endothelial NOS expression in thyroid follicular cells and the variation in its immunoreactivity suggest a possible role for NO in thyrocyte function and/or growth. eNOS immunoreactivity was detected not only in vascular endothelial cells but also in thyroid follicular cells (64) and eNOS mRNA levels were significantly higher in tissues from hyperthyroid versus euthyroid or hypothyroid patients. Treatment with sodium nitroprusside, a precursor of NO, increased cGMP in primary human thyrocytes $(65,66)$ and large amounts of NO were produced by human thyroid follicles in culture (67). However, thyroid hormone levels were not affected in chronic NO deficiency. Thus, $\mathrm{FT}_{4}$ and $\mathrm{FT}_{3}$ levels were similar between control rats $\left(\mathrm{FT}_{3}=1.61 \pm 0.10, \mathrm{FT}_{4}=2.88 \pm 0.43\right)$ and rats treated with L-NAME $75 \mathrm{mg} / 100 \mathrm{ml}$ in drinking water for 4 weeks $\left(\mathrm{FT}_{3}=1.84 \pm 0.09, \mathrm{FT}_{4}=2.79 \pm 0.28\right)$.

Thyroid gland activity affects acute and chronic pressor responsiveness to L-NAME administration. Thus, hypothyroidism induced by the antithyroid drug methimazole reduced acute pressor responsiveness to L-NAME injection in rats (68). Moreover, oral administration of methimazole maintained normal BP levels in L-NAME-treated rats at 25 days after induction of hypertension. These data agree with reports of a BP reduction in several models of experimental hypertension after treatment with thyroidectomy and antithyroid drugs (69-71) and with more recent evidence of the successful use of antithyroid treatments to prevent spontaneous (72, 73), DOCA-salt $(74,75)$, Goldblatt two kidney-one clip and low-renal mass $(76,77)$ arterial hypertension in rats. However, methimazole treatment was unable to reduce BP in L-NAME hypertensive rats after 5 weeks of hypertension induction. These data are similar to those obtained in other models in, which antithyroid treatments also failed to normalize blood pressure in the established phase of genetic (72), DOCA-salt (70) and Goldblatt two kidney-one clip (78) hypertension in rats. The latter findings contrast with observations in a low-renal mass model that methimazole-induced hypothyroidism was equally effective in decreasing BP during both early and established phases of hypertension (76). The reasons for the discrepant effects of hypothyroidism in the established phase of hypertension have not been investigated, although morphological changes and modifications in collagen synthesis or distribution in the vascular wall may be involved (79).

Methimazole administration produced marked reductions in heart weight (HW) and in HW to body weight (BW) ratio in early and established phases of L-NAME hypertension, giving rise to a dissociation between cardiac hypertrophy and hypertension in the established phase (68). This dissociation was also observed in Goldblatt two kidney-one clip hypertension (78) and in DOCA-salt (70) hypertension, where hypothyroidism reversed cardiac hypertrophy regardless of the effect on BP.

Gains in BW are known to be reduced in rats in, which a hypothyroid state has been induced (80). In 
fact, rats treated with L-NAME plus methimazole in the early and established phases showed decreased BW when compared with rats given L-NAME alone (68). Furthermore, a reduction in BW is known to be accompanied by a decrease in BP (81). Hence, the reduction in BW produced by methimazole in rats might play a role in its antihypertensive effect. However, the reduced BW and high BP levels observed in the L-NAME plus methimazole group in the established phase suggests that the BP reduction observed after methimazole treatment is not due to a non-specific effect on the BW (68).

In summary, presence of a hypothyroid state in the rat reduces the pressor effect after acute NO inhibition and prevents L-NAME hypertension but is unable to reverse L-NAME hypertension in rats. Moreover, hypothyroidism reduces relative cardiac hypertrophy in chronically L-NAME-treated rats. However, the mechanism by, which hypothyroidism produces these effects requires further investigation.

The administration of $\mathrm{T}_{4}$ to rats produces a doserelated increase in BP and heart rate (82). It has been reported that rats treated with $\mathrm{T}_{4}$ at a dose that produces a slight increase in BP become hypertensive after partial NOS inhibition with a dose of L-NAME that does not modify BP in control rats. These results indicate that NO may have a counter-regulatory homeostatic role against the prohypertensive effects of thyroid hormone (83).

As the RAS plays an essential role in $\mathrm{T}_{4}$-induced hypertension $(84,85)$ and because NO may interfere with the prohypertensive effects of Ang II $(15,16)$, partial NO blockade may result in predominance of the pressor effects of Ang II. In fact, the administration of losartan produced a marked reduction of BP in rats treated with $\mathrm{T}_{4}$ plus NAME, indicating that Ang II plays an important role in this type of hypertension (83). These observations suggest that an increased NOS activity may play a protective homeostatic role in hyperthyroidism against the prohypertensive effects of thyroid hormone. An important factor in the putative antihypertensive mechanisms of $\mathrm{NO}$ is its antagonistic effects on the pressor actions of Ang II, since administration of losartan greatly attenuated the BP increase in rats treated with $\mathrm{T}_{4}$ plus L-NAME. Moreover, our group observed that acute L-NAME administration to hypertensive hyperthyroid rats which had a lethal effect that was not observed in normal rats (86).

Based on the data reported in this section, it can be concluded that hypothyroidism attenuates the prohypertensive and cardiotrophic effects of the NO inhibitor L-NAME, whereas hyperthyroidism aggravates the effects of NO synthesis inhibition. Moreover, NO has been shown to play a major role in buffering prohypertensive actions of thyroid hormones (Table 1).

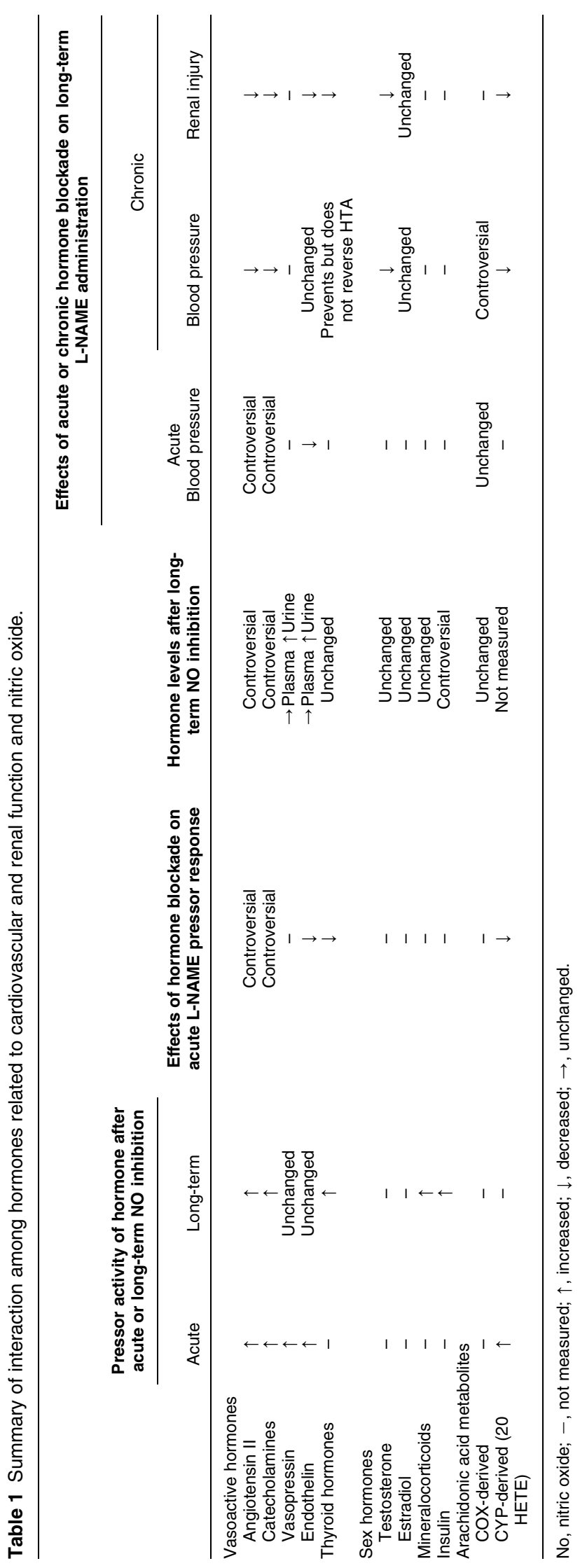

www.eje-online.org 


\section{Sex hormones}

Epidemiological, clinical, and experimental reports have shown that male subjects are more likely to develop hypertension than females $(87,88)$. Numerous studies have suggested that the mechanism by, which estrogens attenuate arterial hypertension in females is due to an enhancement of NO activity (89-91). However, our group observed that male rats develop higher BP, compared with females after L-NAME administration and that the level of hypertension produced is greater in male rats, at least within the first 5 weeks (92). These observations demonstrate that the sexual dimorphic pattern of BP in rats persists, despite NO blockade (92). These data agree with results published by Verhagen et al. (93) using L-NNA, another NOS inhibitor. However, these findings conflict with a report (94) that showed no difference in BP between males and females treated with L-NAME, although the duration of the study was shorter (2 weeks), a lower dose (3-4 mg/kg per day) of L-NAME was used and BP was measured at only one time point and under anesthesia.

Gonadal hormones play a role in determining the different BP levels produced in males and females. Castration attenuates the sexual dimorphic pattern of BP in L-NAME hypertension. Thus, orchidectomy of L-NAME-treated rats was associated with a reduction in $\mathrm{BP}$ to levels found in females, whereas ovariectomy did not affect the level of BP reached in females (92). This suggests that the attenuated hypertension in female is not due to a protective effect of estrogen but rather to a lack of androgens. These observations are consistent with previous findings in SHR $(95,96)$ and secondary types of hypertension (97-99), which showed that orchidectomy significantly attenuated the BP elevation in the male SHR, while ovariectomy had no effect on the development of hypertension in the female.

Estrogenization of males induced by $17 \beta$-estradiol and androgenization of females produced by testosterone administration suppressed the dimorphic pattern of BP in L-NAME hypertension (92). Estrogenization of castrated males produced a reduction of BP similar to that in intact female L-NAME-treated rats (92). However, androgenization of castrated female rats did not change BP in comparison with intact female L-NAME-treated rats (92). The failure of testosterone to affect the development of L-NAME hypertension in castrated female rats is consistent with previous results using the DOCA-salt model (100) and suggests a resistance to the prohypertensive effects of testosterone in females.

Data from different authors indicate that androgens promote exacerbation of hypertension in male humans (101) and animals $(102,103)$ via a mechanism involving RAS $(104,105)$. Because PRA is greater in intact male than female L-NAME-treated hypertensive rats and neutering produced similar PRA levels in all groups, it was proposed that renin might be involved in the gender differences of this type of hypertension (92). In this context, as reported above, there is considerable evidence of a major role for RAS in L-NAME hypertension and experiments have shown that blockade of the RAS prevents development of this model of hypertension $(1,21,22)$.

Intact female L-NAME-treated rats showed a higher degree of cardiac hypertrophy than males, despite having a lower BP (92). This dimorphic pattern disappeared with the castration of both males and females and with the androgenization of females or estrogenization of males (92). Therefore, these data indicate that female L-NAME rats have a greater sensitivity to develop cardiac hypertrophy in response to an increased BP when estrogen is present.

Testosterone and estrogen receptors have both been detected in the kidney (106) and sex hormones can directly influence many processes implicated in the pathogenesis of renal disease. Male L-NAME-treated hypertensive rats showed an increased proteinuria that was not present in female rats (92). The dimorphic pattern of proteinuria disappeared with the castration of male and female rats, and testosterone induced the animals to develop proteinuria, regardless of the BP level (92).

Available data indicate that male rats are more sensitive to the pressor and proteinuric effects of chronic NO inhibition, whereas females are more sensitive to develop cardiac hypertrophy. There is evidence that the RAS may play an important role in the dimorphic patterns of $\mathrm{BP}$ and proteinuria in this type of hypertension. It has also been reported that testosterone has important proteinuric effects, regardless of increased BP.

\section{Mineralocorticoids}

Chronic administration of the mineralocorticoid DOCA induces sodium retention and, in presence of a high salt intake, produces a volume-dependent type of arterial hypertension (107). Experimental protocols in vivo (108) and in vitro (109) suggest that basal NO synthesis is augmented in this model of hypertension and that this increased NO synthesis is apparently a compensatory response for preventing increases in vascular resistance during the development of DOCA-salt hypertension in rats. In contrast, a study of isolated kidneys from DOCAsalt hypertensive rats showed a reduced acetylcholineinduced NO release that was improved by oral administration of L-arginine, which did not, however, influence the time course of systolic BP elevation in the DOCA-salt rats (110).

DOCA treatment without salt supplementation did not produce an elevation in BP, consistent with data from Selye's group on DOCA-salt-induced hypertension (111) and later reports $(48,112)$. The addition of a subpressor dose of L-NAME to DOCA-treated rats induced a BP increase, indicating that NO may play a 
homeostatic role by preventing the pressor effect of DOCA (48). Moreover, when DOCA was added to a pressor dose of L-NAME it produced an additional BP increase and an aggravation of the microalbuminuria and renal parenchymal injury in comparison with rats treated with L-NAME alone $(21,48)$. These outcomes may result from the combined impact on renal function of DOCA-induced antinatriuretic effects and NO inhibition, which appears to be borne out by the reduced PRA and plasma protein levels present in this experimental group $(21,48)$. In saline drinking rats, simultaneous administration of DOCA and L-NAME at subpressor dose exacerbated the course of DOCA-salt hypertension (48). These results confirm that partial NO synthesis inhibition disturbs the homeostatic response to an excess of mineralocorticoids.

DOCA administration produced a significant decrease in plasma protein and suppressed PRA of rats simultaneously treated with L-NAME and DOCA, suggesting that DOCA transforms L-NAME hypertension into a volume-dependent type of hypertension (21, 48). In consonance with this, the administration of DOCA interferes with the preventive effects of losartan against the elevated BP and increased microalbuminuria, hyaline arteriopathy, and glomerulosclerosis of L-NAME hypertension (21). However, K-Laflamme et al. (113) reported that losartan prevented the development of hypertension in uninephrectomized saline drinking rats treated with L-NAME, DOCA, or L-NAME plus DOCA over a short 9-day treatment period.

In summary, impaired NO synthesis increases sensitivity to the pressor effect of mineralocorticoids in presence or absence of increased saline intake. Hence, NO contributes to an adaptive response to excess mineralocorticoids, possibly by facilitating natriuresis and thereby controlling BP.

\section{Insulin}

Several authors have reported that L-NAME hypertension is associated with hyperinsulinaemia and insulin resistance (35). Thus, Erlich et al. (114) showed that L-NAME treatment for 4 weeks resulted in a significant elevation of insulin levels at the end of the experiment, although triglycerides and glucose were unaffected throughout the experiment. They also reported that a combination of L-NAME and verapamil attenuated the hypertension induced by L-NAME and prevented the consequent rise in insulin level. De Angelis Lobo d'Avila et al. (115) observed that L-NAME-induced hypertension was accompanied by an increase in insulin resistance in rats and that exercise reversed peripheral insulin resistance in trained L-NAME-hypertensive rats. However, other authors did not find that acute (116) or chronic (33, 117, 118) L-NAME administration modified plasma concentrations of glucose, insulin, total cholesterol or triglycerides or caused glucose intolerance or insulin resistance. These discrepancies are difficult to explain because the studies used similar doses of L-NAME, duration of experimental procedure and strain of rat.

The most convincing evidence that NO deficiency is related to hyperinsulinaemia and hyperlipidaemia has been provided by studies of disruption of the gene encoding for eNOS. Mice lacking eNOS $(-/-)$ were hypertensive and had fasting hyperinsulinaemia, hyperlipidaemia, and 40\% lower insulin-stimulated glucose uptake versus control mice (119). Cook et al. (120) also reported that mice with targeted disruption of eNOS were hypertensive and insulin resistant and showed fasting hyperinsulinaemia and 1.5- to 2-fold increase in plasma concentrations of cholesterol, triglyceride, and free fatty acids. Plasma leptin levels were 30\% higher in eNOS $(-/-)$ than wild-type mice. Partial gene deletion of eNOS $(+/-)$ predisposed mice to greater high-fat, diet-induced insulin resistance and arterial hypertension (121). Other laboratories reported that inhibition of NO synthesis increases hypertension during chronic glucose infusion in normal rats (122) and accentuates BP elevation in hyperinsulinaemic rats $(123,124)$.

All of the above results indicate that NO deficiency affects not only BP but also glucose and lipid homeostasis, mimicking the human metabolic syndrome X. Therefore, NO deficiency may be a link between metabolic and cardiovascular disease.

\section{Paracrine and autocrine compounds}

In the dog kidney, the full renal vasodilatory potential of NO (or prostaglandin (PG) $\mathrm{I}_{2}$ ) is expressed only in the presence of prostaglandin (or NO) inhibition, suggesting that each autacoid is mutually antagonistic to the synthesis/release of the other (125). In rats, however, Navarro et al. (33) reported that urinary excretion of $\mathrm{PGE}_{2}$, 6-ketoprostaglandin $\mathrm{F}_{1 \alpha}$ and tromboxane $\mathrm{B}_{2}$ were not significantly affected by L-NAME after 5 weeks of treatment. This is in agreement with the observation that acute cyclooxygenase (COX) inhibition did not aggravate hypertension in rats under chronic L-NAME treatment, although additional renal vasoconstriction was produced (126). However, simultaneous chronic administration of indomethacin plus L-NAME did not further modify the reduced RBF, GFR, diuresis and natriuresis of L-NAME-treated hypertensive rats (127). On the other hand, indomethacin $(4 \mathrm{mg} / \mathrm{kg}$ per day, 7 days) partially prevented BP elevation, restored responsiveness to phenylephrine, and enhanced sensitivity to acetylcholine in rats (128). These results suggest that constricting factors arising from the COX pathway contribute to the arterial hypertension and altered vascular reactivity that follows chronic inhibition of NO synthase (128). Moreover, it has been reported that inhibition of COX-2 prevented hypertension and proteinuria in L-NAME-treated rats (129). In contrast, to these findings, Muscara et al. (130) 
reported that chronic selective COX-2 inhibition produced by the daily administration of calecoxib $(10 \mathrm{mg} / \mathrm{kg})$ for 3 weeks elevated the BP of normal and L-NAME-treated rats.

Arachidonic acid (AA) can be metabolized by COX and lipooxygenase enzymes, and a new pathway for its metabolism has recently emerged. Thus, AA is also metabolized by a family of cytochrome P-450 enzymes that catalyze the formation of epoxyeicosatrienoic acid (5 and 6-EET) and 20-hydroxyeicosatrienoic acid (20HETE), among others. 20-HETE and EETs act as second messengers in vascular and renal function (131). Given the importance of these compounds in the regulation of vascular tone and the renal handling of sodium, numerous studies have addressed their role in the pathogenesis of hypertension. There is wide evidence of the altered vascular and renal production of these factors in several models of experimental hypertension (131, 132). NO and 20-HETE interacted to produce reciprocal inhibition in in vivo and in vitro preparations $(131,133)$. NO reversibly binds with heme-containing P450 enzymes, inhibiting their activities and hence their products. NO tonically inhibits production of 20-HETE by the P4504A enzyme. The inhibition of the formation of 20-HETE attenuated the acute hypertensive effects and fall in RBF produced by NO blockade in rats $(133,134)$. The chronic administration of $\mathrm{SnCl}_{2}$, which induces heme-oxygenase and reduces the activity of all CYP enzymes and therefore 20-HETE production, attenuated the development of L-NAME hypertension in rats (135). Moreover, the administration of ABT, an inhibitor of 20-HETE formation, attenuated BP elevation in SHR-L-NAME-treated rats, improved their impaired responsiveness to noradrenaline and isoprenaline and minimized the morphological alterations in kidney and heart observed in SHR-L-NAME-treated rats without ABT treatment (136). Combined treatment with DDMS, inhibitor of 20-HETE synthesis, attenuated the MAP and RVR increase and the decrease in GFR produced by L-NAME in pregnant rats (137). In contrast, with all of these findings, it was recently reported that CYP-450 induction by administration of benzafibrate, a peroxisome proliferator-activated receptor $\alpha$, attenuated hypertension, plasma 8-isoprostane and $\mathrm{NAD}(\mathrm{P}) \mathrm{H}$ oxidase (138) in L-NAME-treated rats. Similar contradictory results have been observed in SHR $(139,140)$ and DOCA-salt hypertensive rats $(138,141)$, in, which inhibition and activation of CYP 450 enzymes attenuated the development of hypertension.

In summary, the role of compounds generated by COX or by CYP-450 enzymes acting on AA in the pathophysiology of NO inhibition-induced hypertension is controversial. The reasons for these discrepant observations have not been defined, but they may by explained by the variety of products with pro- or antihypertensive effects generated by these enzymes.

\section{Other hormones}

In the pituitary gland, NO exerts inhibitory actions on prolactin secretion, growth hormone-induced secretion, and gonadotropin-releasing hormone-induced secretion of luteinizing hormone (142-144). However, it is not known whether they participate in chronic L-NAMEinduced hypertension.

\section{Concluding remarks}

This review presents evidence that NO buffers the prohypertensive effects and renal injuries promoted by classic vasoactive hormones and other hormones related to $\mathrm{BP}$ control and renal function, such as thyroid hormones, mineralocorticoids or insulin. These observations are of potential clinical relevance since the association of an excess of these hormones with diseases that course with reduced NO production, such as atherosclerosis, diabetes or essential hypertension, may aggravate their respective pathogenic effects. Moreover, NO deficiency may represent a link between metabolic and cardiovascular disease. Male rats are more sensitive to the pressor and proteinuric effects of chronic NO inhibition, despite the suggestion by numerous authors that estrogens attenuate arterial hypertension in females via NO activity. Evidence is also provided that the RAS may play an important role in the dimorphic patterns of BP and proteinuria in this type of hypertension, and that testosterone has important proteinuric effects, regardless of BP level. Finally, most of the data discussed in this review were generated in rat models treated with L-arginine analogs. A limitation of these data is that in many instances we do not know whether the observed effects were related to inhibition of eNOS-, inducible NOS (iNOS)- or nNOS-derived NO synthesis. Study of this topic together with analysis of the interaction between $\mathrm{NO}$ and the hormones at cellular level in the main target organs, i.e., heart, vessels and kidney, open new perspectives for the assessment of cardiovascular diseases that require future investigations.

\section{Acknowledgements}

This manuscript was supported by grant SAF200506997 from the Spanish Ministry of Education and Science. We are grateful to R Davies for assistance with the English version.

\section{References}

1 Zatz R \& Baylis C. Chronic nitric oxide inhibition model six years on. Hypertension 199832 958-964. 
2 Arnal JF, Dinh-Xuan AT, Pueyo M, Darblade B \& Rami J. Endothelium-derived nitric oxide and vascular physiology and pathology. Cellular and Molecular Life Sciences $1999 \mathbf{5 5}$ 1078-1087.

3 Kunes J, Hojna S, Kadlecova M, Dobesova Z, Rauchova H, Vokurkova M, Loukotova J, Pechanova O \& Zicha J. Altered balance of vasoactive systems in experimental hypertension: the role of relative NO deficiency. Physiological Research 200453 (Suppl) S23-S34.

4 Vidal MJ, Romero JC \& Vanhoutte PM. Endothelium-derived relaxing factor inhibits renin release. European Journal of Pharmacology $1988 \mathbf{1 4 9} 401-402$.

5 Greenberg SG, He XR, Schnermann JB \& Briggs JP. Effect of nitric oxide on renin secretion. 1. Studies in isolated juxtaglomerular granular cells. American Journal of Physiology $1995 \mathbf{2 6 8}$ F948-F952.

6 Tharaux PL, Dussaule JC, Pauti MD, Vassitch Y, Ardaillou R \& Chatziantoniou C. Activation of renin synthesis is dependent on intact nitric oxide production. Kidney International $1997 \mathbf{5 1}$ 1780-1787.

7 Gardes J, Gonzalez MF, Alhenc-Gelas F \& Menard J. Influence of sodium diet on L-NAME effects on renin release and renal vasoconstriction. American Journal of Physiology $1994 \mathbf{2 6 7}$ F798-F804.

8 Braam B. Renal endothelial and macula densa NOS: integrated response to changes in extracellular fluid volume. American Journal of Physiology 1999276 R1551-R1561.

9 Zanchi A, Schaad NC, Osterheld MC, Grouzmann E, Nussberger J, Brunner HR \& Waeber B. Effects of chronic NO synthase inhibition in rats on renin-angiotensin system and sympathetic nervous system. American Journal of Physiology $1995 \mathbf{2 6 8}$ H2267-H2273.

10 Braam Singh IM, Grams M, Wang WH, Yang T, Killen P, Smart A, Schnermann J \& Brigss JP. Coordinated regulation of renal expression of nitric oxide synthase, renin and angiotensinogen mRNA by dietary salt. American Journal of Physiology $1996 \mathbf{2 7 0}$ F1027-F1037.

11 Braam Persson PB, Baumann JE, Ehmke H, Hackenthal HR, Kirchheim HR \& Nafz B. Endothelium-derived NO stimulates pressure - dependent renin release in conscious dogs. American Journal of Physiology 1993264 F943-F947.

12 Braam Beierwaltes WH. Selective neuronal nitric oxide synthase inhibition blocks furosemide-stimulated renin secretion in vivo. American Journal of Physiology 1995269 F134-F139.

13 Wangensteen R, Sainz J, Rodríguez-Gómez I, Moreno JM, Osuna A \& Vargas F. Chronic blockade of neuronal nitric oxide synthase does not affect long-term control of blood pressure in normal, saline-drinking or deoxycorticosterone-treated rats. Experimental Physiology $2003 \mathbf{8 8} 243-250$.

14 Ollerstam A, Skott O, Ek J, Persson AEG \& Thorup C. Effects of long-term inhibition of neuronal nitric oxide synthase on blood pressure and renin release. Acta Physiologica Scandinavica 2001 $173351-358$.

15 Raij L. Hypertension and cardiovascular risk factors. Role of the Angiotensin II-nitric oxide interaction. Hypertension 200137 767-773.

16 Millatt LJ, Abdel-Rahman EM \& Siragy HM. Angiotensin II and nitric oxide: a question of balance. Regulatory Peptides 199981 $1-10$.

17 Bank N, Aynedjian HS \& Khan GA. Mechanism of vasoconstriction induced by chronic inhibition of nitric oxide in rats. Hypertension 199424 322-328.

18 Qiu C, Engels K \& Baylis C. Angiotensin II and alpha 1-adrenergic tone in chronic nitric oxide blockade-induced hypertension. American Journal of Physiology 1994266 R1470-R1476.

19 Ribeiro MO, Antunes E, de Nucci G, Lovisolo SM \& Zatz R. Chronic inhibition of nitric oxide synthesis: a new model of arterial hypertension. Hypertension 199220 298-303.

20 Jover B, Herizi A, Ventre F, Dupont M \& Mimran A. Sodium and angiotensin in hypertension induced by long-term nitric oxide blockade. Hypertension 199321 944-948.
21 De Gracia MC, Osuna A, O’Valle F, Del Moral RG, Wangensteen R, García del Río C \& Vargas F. Deoxycorticosterone suppresses the effects of losartan in nitric oxide-deficient hypertensive rats. Journal of the American Society of Nephrology $2000 \mathbf{1 1}$ 1995-2000.

22 Fortepiani LA, Rodrigo E, Ortiz MC, Cachofeiro V, Atucha NM, Ruilope LM, Lahera V \& Garcia-Estan J. Pressure natriuresis in nitric oxide-deficient hypertensive rats: effect of antihypertensive treatments. Journal of the American Society of Nephrology 199910 21-27.

23 Pollock DM, Polakowski JS, Divish BJ \& Opgenorth TJ. Angiotensin blockade reverses hypertension during long-term nitric oxide synthase inhibition. Hypertension $199321660-666$.

24 Morton JJ, Beattie EC, Speirs A \& Gulliver F. Persistent hypertension following inhibition of nitric oxide formation in the young Wistar rat: role of renin and vascular hypertrophy. Journal of Hypertension 199311 1083-1088.

25 Burnett JC, Jr. Vasopeptidase inhibition: a new concept in blood pressure management. Journal of Hypertension $1999 \quad 17$ S37-S43.

26 Burrell LM, Rockell MD, Powell J \& Johnston CI. In vivo inhibition of angiotensin converting enzyme and neutral endopeptidase by a dual vasopeptidase inhibitor. American Journal of Hypertension 199912 (Suppl 1) 119.

27 Trippodo NC, Robl JA, Asaad MM, Fox M, Panchal BC \& Schaeffer TR. Effects of omapatrilat in low, normal and high renin experimental hypertension. American Journal of Hypertension $199811363-372$.

28 d'Uscio LV, Ouaschning T, Burmett JC, Jr \& Luscher TF. Vasopeptidase inhibition prevents endothelial dysfunction of resistance arteries in salt-sensitive hypertension in comparison with single ACE inhibition. Hypertension 200137 28-33.

29 Kuro T, Okahara A, Nose M, Ikuse T \& Matsumura Y. Effects of SA7060, a novel dual inhibitor of neutral endopeptidase and angiotensin-converting enzyme, on deoxycorticosterone acetatesalt-induced hypertension in rats. Biological and Pharmaceutical Bulletin 200023 820-825.

30 Zhu ST, Chen YF, Oparil S \& Calhoun DA. Omapatrilat, a vasopeptidase inhibitor, enhances baroreflex gain in spontaneously hypertensive rats. Journal of Hypertension 199917 S65.

31 Rodríguez-Gomez I, Wangensteen R, Atucha NM, O’Valle F, Del Moral RG, García Estañ J, Vargas F \& Osuna A. Effects of omapatrilat on blood pressure and renal injury in L-NAME and L-NAME plus DOCA-treated rats. American Journal of Hypertension $20031633-38$.

32 Sander M \& Victor RG. Neural mechanisms in nitric-oxidedeficient hypertension. Current Opinion in Nephrology and Hypertension 19998 61-73.

33 Navarro J, Sanchez A, Saiz J, Ruilope LM, Garcia-Estan J, Romero JC, Moncada S \& Lahera V. Hormonal, renal, and metabolic alterations during hypertension induced by chronic inhibition of NO in rats. American Journal of Physiology 1994267 R1516-R1521.

34 Liu Y, Tsuchihashi T, Kigiyama S, Matsumura K, Abe I \& Fujishima M. Central and peripheral mechanisms involved in hypertension induced by chronic inhibition of nitric oxide synthase in rats. Journal of Hypertension 199816 1165-1173.

35 Baron AD, Zhu JS, Marshall S, Irsula O, Brechtel G \& Keech C. Insulin resistance after hypertension induced by the nitric oxide synthesis inhibitor L-NMMA in rats. American Journal of Physiology 1995269 E709-E715.

36 Lacolley PJ, Lewis SJ \& Brody MJ. Role of sympathetic nerve activity in the generation of vascular nitric oxide in urethaneanesthetized rats. Hypertension 199117 881-887.

37 Pucci ML, Lin L \& Nasjletti A. Pressor and renal vasoconstrictor effects of $N^{\omega}$-nitro-L-arginine as affected by blockade of pressor mechanisms mediated by the sympathetic nervous system, angiotensin, prostanoids and vasopressin. Journal of Pharmacology and Experimental Therapeutics $1992261240-245$. 
38 Manning RD, Hu L \& Williamson TD. Mechanisms involved in the cardiovascular-renal actions of nitric oxide inhibition. Hypertension 199423 951-956.

39 Scrogin KE, Hatton DC, Chi Y \& Luft FC. Chronic nitric oxide inhibition with L-NAME: effects on autonomic control of the cardiovascular system. American Journal of Physiology $1998 \mathbf{2 7 4}$ R367-R374.

40 Sander M, Hansen J \& Victor RG. The sympathetic nervous system is involved in the maintenance but not initiation of the hypertension induced by $N^{\omega}$-nitro-L-arginine methyl ester. Hypertension 199730 64-70.

41 Fitzgerald SM \& Brands MW. Hypertension in L-NAME-treated diabetic rats depends on an intact sympathetic nervous system. American Journal of Physiology 2002282 R1070-R1076.

42 Wangensteen R, O'Valle F, Del Moral RG, Vargas F \& Osuna A. Chronic alpha1-adrenergic blockade improves hypertension and renal injury in L-NAME and low-renin L-NAME-DOCA hypertensive rats. Medical Science Monitor 20028 BR378-BR384.

43 Nylen A, Skagerberg G, Alm P, Larsson B, Holmqvist B \& Anderson KE. Nitric oxide synthase in the hypothalamic paraventricular nucleus of the female rat; organization of spinal projections and coexistence with oxytocin or vasopressin. Brain Research 2001908 10-24.

44 Wolff DJ \& Gribin BJ. The inhibition of the constitutive and inducible nitric oxide synthase isoforms by indazole agents. Archives of Biochemistry and Biophysics 1994311 300-306.

45 Moore PK \& Bland-Ward PA. 7-Nitroindazole: an inhibitor of nitric oxide synthase. Methods in Enzymology $1996 \mathbf{2 6 8}$ 393-398.

46 Ventura RR, Giusti-Paiva A, Gomes DA, Elias LL \& AntunesRodrigues J. Neuronal nitric oxide synthase inhibition differentially affects oxytocin and vasopressin secretion in salt loaded rats. Neuroscience Letters 2005379 75-80.

47 Xu L, Carter EP, Ohara M, Martin PY, Rogachev B, Morris K, Cadnapaphornchai M, Knotek M \& Schrier RW. Neuronal nitric oxide synthase and systemic vasodilation in rats with cirrhosis. American Journal of Physiology 2000279 F1110-F1115.

48 Alvarez G, Osuna A, Wangensteen R \& Vargas F. Interaction between nitric oxide and mineralocorticoids in the long-term control of blood pressure. Hypertension 200035 752-757.

49 Deng LY, Thibault G \& Schiffring EL. Effect of hypertension induced by nitric oxide synthase inhibition on structure and function of resistance arteries in the rat. Clinical and Experimental Hypertension 199315 527-537.

50 Vanhoutte PM, Lüscher TF \& Gräser T. Endothelium-dependent contractions. Blood Vessels 199128 74-83.

51 Boulanger C \& Lüscher TF. Release of endothelin from porcine aorta: Inhibition by endothelium-derived nitric oxide. Journal of Clinical Investigation 199085 587-590.

52 Vanhoutte PM, Auch-Schwelk W, Boulanger C, Janssen PA, Katusic ZS, Komori K, Miller VM, Schini VB \& Vidal M. Does endothelin-1 mediate endothelium-dependent contractions during anoxia? Journal of Cardiovascular Pharmacology 198913 (Suppl 5) S124-S128.

53 Banting JD, Friberg P \& Adams MA. Acute hypertension after nitric oxide synthase inhibition is mediated primarily by increased endothelin vasoconstriction. Journal of Hypertension 199614 975-981.

54 Qiu C, Engels K \& Baylis C. Endothelin modulates the pressor actions of acute systemic nitric oxide blockade. Journal of the American Society of Nephrology 19956 1476-1481.

55 Richard V, Hogie M, Clozel M, Loffler BM \& Thuillez C. In vivo evidence of an endothelin-induced vasopressor tone after inhibition of nitric oxide synthesis in rats. Circulation 199591 771-775.

56 Clozel M \& Breu V. The role of ET(B) receptors in normotensive and hypertensive rats as revealed by the nonpeptide selective ET(B) receptor antagonist Ro 46-8443. FEBS letters $1996 \mathbf{3 8 3} 42-45$.
57 Fujihara CK, De Nucci G \& Zatz R. Do ETA receptors participate in the hemodynamic and renal effects of chronic nitric oxide blockade? Journal of Cardiovascular Pharmacology 199526 (Suppl 3) $\mathrm{S} 462-\mathrm{S} 465$.

58 Nakamura T, Ohyama Y, Masuda H, Kurasina T, Saito Y, Kato T, Sumino H, Sato K, Sakamaki T, Sasaki A \& Nagai R. Chronic blockade of nitric oxide synthesis increases urinary endothelin-1 excretion. Journal of Hypertension 199715 373-381.

59 Moreau P, Takase H, Kung CF, Shaw S \& Luscher TF. Blood pressure and vascular effects of endothelin blockade in chronic nitric oxide-deficient hypertension. Hypertension 199729 763-769.

60 Sventek P, Turgeon A \& Schiffrin EL. Vascular endothelin-1 gene expression and effect on blood pressure of chronic ETA endothelin receptor antagonism after nitric oxide synthase inhibition with L-NAME in normal rats. Circulation 199795 240-244.

61 Fernández-Rivas A, García-Estañ J \& Vargas F. Effects of chronic increased salt intake on nitric oxide synthesis inhibition-induced hypertension. Journal of Hypertension 199513 123-128.

62 Miller WL, Redfield MM \& Burnett CJ, Jr. Integrated cardiac, renal, and endocrine actions of endothelin. Journal of Clinical Investigation 198983 317-320.

63 Fortepiani LA, Janvier JJ, Ortíz MC, Atucha MM \& García-Estañ J. Pressure natriuresis in nitric oxide deficient hypertensive rats: effects of endothelin blockade. Journal of Hypertension 199917 287-291.

64 Colin IM, Kopp P, Zbären J, Häberli A, Grizzle WE \& Jameson LJ. Expression of nitric oxide synthase III in human thyroid follicular cells: evidence for increased expression in hyperthyroidism. European Journal of Endocrinology 1997136 649-655.

65 Millatt LJ, Jackson R, Williams BC \& Whitley GStJ. Nitric oxide stimulates cyclic GMP in human thyrocytes. Journal of Molecular Endocrinology 199310 163-169.

66 Rasmussen A, Di Marco R, Diamant M, Feldt-Rasmussen U \& Bendtzen K. Nitric oxide production is not involved in the effects of interleukin-1 $\beta$ on cAMP, thyroglobulin and interleukin- 6 in TSH-stimulated human thyroid cells. Autoimmunity 199419 239-245.

67 Kasai K, Hattori Y, Nakanishi N, Manaka K, Banba N, Motohashi S \& Shimoda S. Regulation of inducible nitric oxide production by cytokines in human thyrocytes in culture. Endocrinology 1995136 4261-4270.

68 Vargas F, Fernández-Rívas A \& Osuna A. Effects of methimazole in the early and established phases of L-NAME hypertension. European Journal of Endocrinology 1996135 506-513.

69 Chappel CI, Rona G, Reversz C \& Cahill J. Effect of propylthiouracil on adrenal-regeneration hypertension in the rat. Proceedings of the Society for Experimental Biology and Medicine 195898 23-26.

70 Salgado E. Effect of thyroidectomy on hypertension, nephrosclerosis and cardiac lesions produced by deoxycorticosterone acetate (DCA) treatment in the rat. Endocrinology 195455 112-115.

71 Fregly MJ. Effects of propylthiouracil on development and maintenance of renal hypertension in rats. American Journal of Physiology 1958194 149-154.

72 Rioux F \& Berkowitz BM. Role of the thyroid gland in the development and maintenance of spontaneous hypertension in rats. Circulation Research 197740 306-312.

73 Rodger RL \& McNeill JH. Antihypertensive effect of thyroidectomy in SHR: associated changes in heart performance. American Journal of Physiology $1986 \mathbf{2 5 0} 600-605$.

74 Rials SJ, Sullivan MM \& Hansen JR. Effects of thyroidectomy on blood pressure of DOCA-hypertensive rats. Federation Proceedings 1982411660.

75 Vargas F, García del Rio C, Luna JD, Haro JM \& Osorio C. Studies on thyroid activity in deoxycorticosterone-salt and Goldblatt two-kidney, one-clip hypertensive rats. Acta Endocrinologica $1988 \mathbf{1 1 8} 22-30$.

76 Andrade J, Haro JM, Jódar E, Luna JD \& Vargas F. Effects of methimazole on low renal mass hypertension: changes on blood pressure and pressor responsiveness to vasoconstrictors. Pharmacology $199244315-323$. 
77 Andrade JL, Haro JM, Sabio JM, García del Rio C \& Vargas F. Effects on renal function and digoxin-like immunoreactivity produced by methimazole in low-renal mass hypertension. Clinical and Experimental Hypertension. Part A 199214 1003-1016.

78 Vargas F, Castillo MA \& Haro JM. Methimazole treatment reduces cardiac hypertrophy and mortality without a concomitant reduction in blood pressure in established Goldblatt two-kidney one clip hypertension. Experientia 199248 755-758.

79 Folkow B. Structural factor in primary and secundary hypertension. Hypertension 199016 89-101.

80 Bradley SE, Stéphan F, Coelho JB \& Reville P. The thyroid and the kidney. Kidney International 19746 346-365.

81 Epstein FH. Estimating the effect of preventing obesity on total mortality and hypertension. International Journal of Obesity 1979 3 163-166.

82 Vargas F, Moreno JM, Rodríguez-Gómez I, Wangensteen R, Osuna A, Alvarez-Guerra M \& García-Estañ J. Vascular and renal function in experimental thyroid disorders. European Journal of Endocrinology 2006154 197-212.

83 Rodríguez-Gómez I, Sainz J, Wangensteen R, Moreno JM, Duarte J, Osuna A \& Vargas F. Increased pressor ensitivity to chronic nitric oxide deficiency in hyperthyroid rats. Hypertension 200342 220-225.

84 García del Río C, Moreno MRR, Osuna A, Luna JD, García-Estañ J \& Vargas F. Role of the renin-angiotensin system in the development of thyroxine-induced hypertension. European Journal of Endocrinology 1997136 656-660.

85 García-Estañ J, Atucha N, Quesada T \& Vargas F. Involvement of the renin-angiotensin in the reduced pressure-natriuresis response of hyperthyroid rats. American Journal of Physiology 1995268 E897-E901.

86 Sabio JM, Garcia-Estañ J, García del Río C \& Vargas F. Effects of Nnitro L-arginine metyl ester on the response to $\mathrm{NaCl}$ load in hyper and hypothyroid rats. Hormone and Metabolic Research 199426 409-412.

87 Chen YF. Sexual dimorphism of hypertension. Current Opinion in Nephrology and Hypertension 19966 181-185.

88 Reckelhoff JF. Gender differences in the regulation of blood pressure. Hypertension 200137 1199-1208.

89 Sasaki T, Ohno Y, Otsuka K, Suzawa T, Suzuki H \& Saruta T. Oestrogen attenuates the increases in blood pressure and platelet aggregation in ovariectomized and salt-loaded Dahl salt-sensitive rats. Journal of Hypertension 2000 18 911-917.

90 Chen Z, Yuhanna IS, Galcheva-Gargova ZI, Karas RH, Mendelsohn ME \& Shaul PW. Estrogen receptor alpha mediates the nongenomic activation of endothelial nitric oxide synthase by estrogen. Journal of Clinical Investigation 1999103 401-406.

91 Weiner CP, Lizasoain I, Baylis SA, Knowles RG, Charles IG \& Moncada S. Induction of calcium-dependent nitric oxide synthases by sex hormones. PNAS 199491 5212-5216.

92 Sainz J, Osuna A, Wangensteen R, Luna JD, Rodríguez-Gómez I, Duarte J, Moreno JM \& Vargas F. Role of sex, gonacedtomy and sex hormones in the development of nitric oxide inhibition-induced hypertension. Experimental Physiology 200489 155-162.

93 Verhagen AM, Attia DM, Koomans HA \& Joles JA. Male gender increases sensitivity to proteinuria induced by mild NOS inhibition in rats: role of sex hormones. American Journal of Physiology 2000279 F664-F670.

94 Reckelhoff JF, Hennington BS, Moore AG, Blanchard EJ \& Cameron J. Gender differences in the renal nitric oxide (NO) system. Dissociation between expression of endothelial NO synthase and renal hemodynamic response to NO synthase inhibition. American Journal of Hypertension 199811 97-104.

95 Chen YF \& Meng QC. Sexual dimorphism of blood pressure in spontaneously hypertensive rats is androgen dependent. Life Sciences $1991 \mathbf{4 8} 85-96$.

96 Reckelhoff JF, Zhang H, Srivastava K \& Granger JP. Gender differences in hypertension in spontaneously hypertensive rats: role of androgens and androgen receptor. Hypertension 199934 920-923.
97 Masubuchi Y, Kumai T, Uematsu A, Komoriyama K \& Hirai M. Gonadectomy-induced reduction in blood pressure in adult spontaneously hypertensive rats. Acta Endocrinologica 1982 101 154-160.

98 Crofton JT, Share L \& Brooks DP. Gonadectomy abolishes the sexual dimorphism in DOC-salt hypertension in the rat. Clinical and Experimental Hypertension. Part A 198911 1249-1261.

99 Malyusz M, Ehrens HJ \& Wrigge P. Effects of castration on the experimental renal hypertension of the rat. Nephron 198540 96-99.

100 Crofton JT \& Share L. Gonadal hormones modulate deoxycorticosterone-salt hypertension in male and female rats. Hypertension 199729 494-499.

101 Sealey JE, Atlas SA \& Laragh JH. Prorenin and other large molecular weight forms of renin. Endocrine Reviews 19801 365-391.

102 Nielsen AH, Johannessen A \& Poulsen K. Inactive plasma renin exhibits sex difference in mice. Clinical science 198976 439-446.

103 Chen YF, Naftilan AJ \& Oparil S. Androgen-dependent angiotensinogen and renin messenger RNA expression in hypertensive rats. Hypertension $199219456-463$.

104 Ellison KE, Ingelfinger JR, Pivor M \& Dzau VJ. Androgen regulation of rat renal angiotensinogen messenger RNA expression. Journal of Clinical Investigation 198983 1941-1945.

105 Katz FH \& Roper EF. Testosterone effect on renin system in rats. Proceedings of the Society for Experimental Biology and Medicine 1977155 330-333.

106 Davidoff M, Caffier H \& Schiebler TH. Steroid hormone binding receptors in the rat kidney. Histochemistry 198069 39-48.

107 Hollenberg NK, Coletti C \& Passan D. Hypertension, volume and vasoconstriction: studies on the renal blood supply in SHR, WKY and DOCA-salt rats models. Hypertension Research $1992153-11$.

108 King AJ, Mercer P, Troy JL \& Brenner BM. Endothelium-derived relaxing factor and the vascular reply to systemic hypertension. Journal of the American Society of Nephrology 19912 1072-1077.

109 Bockman CS, Jefries WB, Pettinger WA \& Abel PW. Enhanced release of endothelium-derived relaxing factor in mineralocorticoid hypertension. Hypertension 199220 304-313.

110 Hayakawa H, Hirata Y, Sizuki E, Kimura K, Kikuchi K, Nagano T, Hirobe M \& Omata M. Long-term administration of L-Arginine improves nitric oxide release from kidneys in deoxycorticosterone acetate salt hypertensive rats. Hypertension 199423 752-756.

111 Selye H, Hall CE \& Rowley EM. Malignant hypertension produced by treatment with desoxicorticosterone acetate and sodium chloride. Canadian Medical Association Journal 194349 88-92.

112 Vargas F, Casanova I, Haro JM, Luna JD \& García del Río C. The handling of $\mathrm{NaCl}$ load in rats during DOCA-salt and Goldblatt 2 kydney-1 clip hypertension development. Revista Española de Fisiología 198844 185-190.

113 K-Laflamme A, Oster L, Cardinal R \& de Champlain J. Role of NO and angiotensin II in the early development of endothelial functions impairment and cardiac hypertrophy in deoxycorticosterone acetate-salt hypertension. Canadian Journal of Physiology and Pharmacology 199876 665-675.

114 Erlich Y \& Rosenthal T. Chronic hypertension leads to hyperinsulinemia in Sprague-Dawley rats treated with nitric oxide synthase inhibitor. American Journal of Hypertension 1998 11 1129-1133.

115 De Angelis Lobo d'Avila K, Gadonski G, Fang J, Dall'Ago P, Albuquerque VL, Peixoto LR, Fernandes TG \& Irigoyen MC. Exercise reverses peripheral insulin resistance in trained L-NAME-hypertensive rats. Hypertension 199934 768-772.

116 Bursztyn M, Raz I, Mekler J \& Ben-Ishay D. Effect of acute N-nitroL-arginine methyl ester (L-NAME) hypertension on glucose tolerance, insulin levels, and [3H]-deoxyglucose muscle uptake. American Journal of Hypertension 199710 683-686.

117 Swislocki A, Eason T \& Kaysen GA. Oral administration of the nitric oxide biosynthesis inhibitor, $N$-nitro-L-arginine methyl 
ester (L-NAME), causes hypertension, but not glucose intolerance or insulin resistance, in rats. American Journal of Hypertension 19958 1009-1014.

118 Nakaya Y, Ishimura N, Takishita E \& Takahashi A. Chronic feeding of a nitric oxide synthase inhibitor induces postprandial hypertriglyceridemia in type 2 diabetic model rats, Otsuka LongEvans Tokushima Fatty rats, but not in nondiabetic rats. Metabolism: Clinical and Experimental 200251 702-707.

119 Duplain H, Burcelin R, Sartori C, Cook S, Egli M, Lepori M, Vollenweider P, Pedrazzini T, Nicod P, Thorens B \& Scherrer U. Insulin resistance, hyperlipidemia, and hypertension in mice lacking endothelial nitric oxide synthase. Circulation $2001 \mathbf{1 0 4}$ 342-345.

120 Cook S, Hugli O, Egli M, Vollenweider P, Burcelin R, Nicod P, Thorens B \& Scherrer U. Clustering of cardiovascular risk factors mimicking the human metabolic syndrome $\mathrm{X}$ in eNOS null mice. Swiss Medical Weekly 2003133 360-363.

121 Cook S, Hugli O, Egli M, Menard B, Thalmann S, Sartori C, Perrin C, Nicod P, Thorens B, Vollenweider P, Scherrer U \& Burcelin R. Partial gene deletion of endothelial nitric oxide synthase predisposes to exaggerated high-fat diet-induced insulin resistance and arterial hypertension. Diabetes $2004 \mathbf{5 3}$ 2067-2072.

122 Claxton CR, Brands MW, Fitzgerald SM \& Cameron JA. Inhibition of nitric oxide synthesis potentiates hypertension during chronic glucose infusion in rats. Hypertension 200035 451-456.

123 Bursztyn M, Mekler J, Peleg E \& Bernheim J. Subpressor dose of L-NAME unmasks hypertensive effect of chronic hyperinsulinemia. Hypertension 200036 872-877.

124 Fang TC, Wu CC \& Huang WC. Inhibition of nitric oxide synthesis accentuates blood pressure elevation in hyperinsulinemic rats. Journal of Hypertension 200119 1255-1262.

125 Lahera V, Salom MG, Fiksen-Olsen MJ, Raij L \& Romero JC. Effects of NG-monomethyl-L-arginine and L-arginine on acethylcholine renal response. Hypertension 199015 659-663.

126 Baylis C, Slangen B, Hussain S \& Weaver C. Relatioship between basal NO release and cyclooxigenase products in the normal rat kidney. American Journal of Physiology 1996271 R1327-R1334.

127 García-Estañ J, Navarro J, Atucha NM, Quesada T, Romero JC, Cachofeiro V \& Lahera V. Chronic effect of nitric oxide and prostaglandin inhibition on pressure diuresis and natriuresis in rats. Kidney International 199649 S141-S143.

128 Da Cunha V, Rossoni LV, Oliveira PA, Poton S, Pretti SC, Vassallo DV \& Stephanon I. Cycloxigenase inhibition reduces blood pressure elevation and vascular reactivity dysfunction caused by inhibition of nitric oxide synthase in rats. Clinical and Experimental Hypertension 200022 203-215.

129 Tomida T, Numaguchi Y, Nishimoto Y, Tsuzuki M, Hayashi Y, Imai H, Matsui H \& Okumura K. Inhibition of COX-2 prevents hypertension and proteinuria associated with a decrease of 8-isoPGF2 $\alpha$ formation in L-NAME treated rats. Journal of Hypertension 200321 601-609.

130 Muscara NM, Vergnolle N, Lovren F, Triggle CR, Elliot SN, Asfaha S \& Wallace JL. Selective cyclo-oxygenase-2 inhibition with celecoxib elevates blood pressure and promotes leukocyte adherence. British Journal of Pharmacology $2000 \quad \mathbf{1 2 9}$ $1423-1430$.

131 Roman RJ. P-450 metabolites of arachidonic acid in the control of cardiovascular function. Physiological Reviews 200182 131-185.
132 Moreno C, Maier KG, Hoagland KM, Yu M \& Roman RJ. Abnormal pressure-natriuresis in hypertension: Role of cytochrome $\mathrm{P} 450$ metabolites of arachidonic acid. American Journal of Hypertension $2001 \mathbf{1 4}$ 90S-97S.

133 Alonso-Galicia M, Drummond HA, Reddy KK, Falck JR \& Roman RJ. Inhibition of 20-HETE production contributes to the vascular responses to nitric oxide. Hypertension 199729 320-325.

134 Oyekan A \& McGiff JC. Functional response of the rat kidney to inhibition of nitric oxide synthesis: role of cytochrome P-450derived arachidonate metabolites. British Journal of Pharmacology 1998125 1065-1073.

135 Sanchez-Mendoza MA, Martinez-Ayala SO, HernandezHernandez JA, Zuñiga-Sosa L, Pastelin-Hernandez G \& Escalante-Acosta BA. Participation of nitric oxide and arachidonic acid metabolites via cytochrome P-450 in the regulation of arterial blood pressure. Archivos de Cardiología de México 200373 98-104.

136 Benter IF, Francis I, Cojocel C, Juggi JS, Yousif MH \& Canatan H. Contribution of Cytochrome P450 metabolites of arachidonic acid to hypertension and end-organ damage in spontaneously hypertensive rats treated with L-NAME. Autonomic \& Autacoid Pharmacology 200525 143-154.

137 Huang H, Zhou Y, Raju VT, Du J, Chang HH, Wang CY, Brands MW, Falck JR \& Wang MH. Renal 20-HETE inhibition attenuates changes in renal hemodynamics induced by L-NAME treatment in pregnant rats. American Journal of Physiology 2005 289 F1116-F1122.

138 Newaz M, Blanton A, Fidelis P \& Oyekan AO. NAD(P)H oxidase/nitric oxide interaction in peroxisome proliferators activated receptor $\alpha(P P A R \alpha)$-mediated cardiovascular effects. Mutation Research $2005 \mathbf{5 7 9} 163-171$.

139 Escalante B, Sacerdoti D, Davidian MM, Laniado-Schwartzman M \& McGiff JC. Chronic treatment with tin normalizes blood pressure in spontaneously hypertensive rats. Hypertension 1991 $17776-779$

140 Shatara RK, Quest DW \& Wilson TW. Fenofibrate lowers blood pressure in two genetic model of hypertension. Canadian Journal of Physiology and Pharmacology 200078 367-371.

141 Oyekan AO, McAward K, Conetta J, Rosenfeld L \& McGiff JC. Endothelin-1 and CYP450 arachidonate metabolites interact to promote tissue injury in DOCA-salt hypertension. American Journal of Physiology 1999276 R766-R775.

142 Ceccatelli S, Hulting AL, Zhang X, Gustafsson L, Villar M \& Hokfelt T. Nitric oxide synthase in the rat anterior pituitary gland and the role ofnitric oxide in regulation of luteinizing hormone secretion. PNAS 199390 11292-11296.

143 Duvilanski BH, Zambruno C, Seilicovich A, Pisera D, Lasaga M, Diaz MC, Belova N, Rettori V \& McCann SM. Role of nitric oxide in control of prolactin release by the adenohypophysis. PNAS 1995 92 170-174.

144 Kato M. Involvement of nitric oxide in growth hormone (GH)releasing hormone-induced $\mathrm{GH}$ secretion in rat pituitary cells. Endocrinology $19921312133-2138$.

Received 3 July 2006

Accepted 10 October 2006 